\title{
5-HTr Expression in Primary Trigeminal Neurons Following Injury
}

\author{
Ombretta Mameli ${ }^{*}$, Antonella Russo ${ }^{2}$, Stefania Stanzani ${ }^{2}$, Giovanni Tringali ${ }^{3}$, Elio Insirello ${ }^{3}$, \\ Marcello Alessandro Caria ${ }^{1}$, Pier Luigi De Riu ${ }^{1}$ \\ ${ }^{1}$ Department of Clinical and Experimental Medicine, Human Physiology Division, University of Sassari, Sassari, Italy \\ ${ }^{2}$ Department of Physiological Sciences, University of Catania, Catania, Italy \\ ${ }^{3}$ Istituto di Ricerca Medica e Ambientale, Catania, Italy \\ Email: ${ }^{*}$ fisiou@uniss.it
}

Received May 9, 2012; revised June 14, 2012; accepted July 11, 2012

\begin{abstract}
Trigeminal ganglia neurons significantly affect the amplitude and type of 5-HT receptor gene expression following activation of their axon terminals and sensitisation by painful stimuli. Moreover, these neurons significantly alter gene expression in cytoskeletal proteins following injury. The aim of the present study was to determine whether peripheral and/or central deafferenting lesions affect gene expression in serotonergic receptors that are involved in pain transmission. Adult rats were subjected to unilateral ablation of the facial sensory and motor cortices. Fifteen days after the surgery, degeneration of the cortico-trigeminal pathway was observed. Presynaptic deafferentation of the primary trigeminal neurons and central afferents of the contralateral ganglia was conducted. As a consequence of the excision of the meninges covering the ablated cortices, the peripheral axotomy of the trigeminal-vascular primary neurons of the ipsilateral side was induced. Serotonergic receptor $\left(5-\mathrm{HT}_{5 \mathrm{~A} / 5 \mathrm{~B} / 1 \mathrm{~B} / \mathrm{D} / \mathrm{F})}\right)$ gene expression was analysed in both sides of the trigeminal ganglia neurons. The results of the present study showed a significant increase in 5-HT $\mathrm{HA}_{5 \mathrm{AB} / 1 \mathrm{~B} / 1 \mathrm{D}}$ receptor gene expression in the primary sensory neurons of both ganglia, with the highest levels of expression noted in the ganglia contralateral to the lesion. 5- $\mathrm{HT}_{1 \mathrm{~F}}$ receptor expression, however, was more strongly expressed in the ganglia ipsilateral to the lesion. Our results also confirm that the adaptive response of primary trigeminal neurons to injury involves anatomical remodelling, as well as changes in receptor gene expression involved in sensory transmission. This may explain the distortion of sensory signals observed in trigeminal neuropathic states, and may lead to the development of novel pharmacological interventions.
\end{abstract}

Keywords: Sensory Neurons Plasticity; Trigeminal Ganglia Neurons; Axotomy; Pre-Synaptic Deafferentation; 5-HT Receptors

\section{Introduction}

The ability of primary sensory neurons to anatomically remodel following experimentally induced lesions has been shown in trigeminal ganglia. In response to peripheral axotomy and central deafferentation, sensory primary neurons of the trigeminal ganglia overexpress growth proteins, i.e., alpha-tyrosinated tubulin, and undergo significant terminal sprouting and central afferent neosynaptogenesis [1]. Moreover, these neuronal changes have been also described following specific functional activities and during stimulation of the axon terminals [2-5]. Indeed, during painful stimuli-induced ac-

${ }^{*}$ Corresponding author. tivation and sensitisation, the type and magnitude of 5-HT receptor gene expression in trigeminal-vessel primary neurons is significantly altered [6-8]. Previous studies have shown that cerebral vessel pain sensitivity is related to gene expression in 5-HT receptors ([9], for a review). The modulation of gene expression in serotonergic receptors in response to injury, however, has not been investigated.

Therefore, the present study investigated the plastic changes in primary trigeminal neurons observed in response to injury. Primary trigeminal neurons are involved in sensory conduction of peripheral stimuli to the CNS. Thus, the aim of our study was to determine whether primary trigeminal neurons alter 5-HT receptor gene expression in response to experimental injury. 


\section{Results}

\subsection{Group I: Primary Trigeminal Neurons Underwent Peripheral Axotomy and Pre-Synaptic Deafferentation of Their Central Afferents}

During the recovery period, this group of animals displayed mild motor impairments in the right forelimb as well as rotation of the head and neck on the operated side. These symptoms disappeared within 48 hours.

Significant bilateral increases in 5-HT receptor mRNA expression were noted for each receptor in the primary trigeminal neurons of experimental animals compared with controls. Significant differences were also noted between the sides (Figure 1). The relative expression of 5HT receptor ${ }_{5 \mathrm{~A}}, 5 \mathrm{~B}, 1 \mathrm{~B}$, and ${ }_{1 \mathrm{D}}$ genes in trigeminal (TG) neurons on the right side, contralateral to the ablated cortex (left side), was significantly higher than that on the ipsilateral side. The expression of $5-\mathrm{HT}_{5 \mathrm{~A}}, 5-\mathrm{HT}_{5 \mathrm{~B}}$, $5-\mathrm{HT}_{1 \mathrm{~B}}$, and 5- $\mathrm{HT}_{1 \mathrm{D}}$ receptors on the right side was $6.24 \pm$ $2.3,5.82 \pm 1.9,6.1 \pm 2.2$, and $5.48 \pm 1.4$ (mean $\pm \mathrm{SD}$ ), respectively, versus $3.16 \pm 0.58,2.87 \pm 1.1,3.92 \pm 1.6$, and $2.84 \pm 0.13$ on the left side. By contrast, $5-\mathrm{HT}_{1 \mathrm{~F}}$ receptor expression was significantly higher in the primary trigeminal neurons ipsilateral to the ablated cortex compared with neurons on the contralateral side $(2.24 \pm 0.31$ vs. $1.24 \pm 0.21$ ). The differences in 5 -HT receptor gene expression on both sides of the ganglia neurons are displayed in Table 1.

\subsection{Group II: Primary Trigeminal Neurons That Underwent Only a Peripheral Axotomy}

No significant differences were noted in the experimental group compared with the sham-operated controls in Group III during the recovery period. Significantly higher 5-HT receptor mRNA expression was noted for each receptor in the primary trigeminal neurons ipsilateral to the ablated meninges compared with the expression detected in the contralateral ganglia. In particular, the expression of $5-\mathrm{HT}_{5 \mathrm{~A}}, 5-\mathrm{HT}_{5 \mathrm{~B}}, 5-\mathrm{HT}_{1 \mathrm{~B}}, 5-\mathrm{HT}_{1 \mathrm{D}}$, and $5-\mathrm{HT}_{1 \mathrm{~F}}$ receptors on the Gasser neurons ipsilateral to the ablated meninges was $1.87 \pm 0.28,1.38 \pm 0.24,1.61 \pm 0.18,1.58 \pm 0.3$, and $2.03 \pm 0.35$, respectively, whereas the levels on the contralateral side did not differ from controls. The expression of $5-\mathrm{HT}_{1 \mathrm{~F}}$ receptors, however, was significantly higher compared with that of the other receptors. Significant differences in 5-HT receptor gene expression in both sides of the ganglia are shown in Table $\mathbf{1}$.

\subsection{Group III: Sham Operated Animals}

The sham-operated animals did not differ from animals not subjected to experimental procedures during the re-
Table 1. Statistical analysis of 5-HT receptors gene expression detected in experimental ganglia (Groups $\mathrm{I}^{\circ}-\mathrm{II}^{\circ}$ ). (a): Statistical significance assessed by Wilcoxon signed-rank test; (b)-(c): Statistical significance assessed by the Mann-Whitney $U$-test.

(a)

\begin{tabular}{|c|c|}
\hline $1 \mathrm{~B}$ right $\mathrm{I}^{\circ} \mathrm{vs} 1 \mathrm{~B}$ left $\mathrm{I}^{\circ}$ & $\mathrm{P}<0.05$ \\
\hline $1 \mathrm{D}$ right $\mathrm{I}^{\circ} \mathrm{vs} 1 \mathrm{D}$ left $\mathrm{I}^{\circ}$ & $\mathrm{P}<0.05$ \\
\hline $1 \mathrm{~F}$ right $\mathrm{I}^{\circ} \mathrm{vs} 1 \mathrm{~F}$ left $\mathrm{I}^{\circ}$ & $\mathrm{P}<0.05$ \\
\hline $5 \mathrm{~A}$ right $\mathrm{I}^{\circ}$ vs $5 \mathrm{~A}$ left $\mathrm{I}^{\circ}$ & $\mathrm{P}<0.05$ \\
\hline $5 \mathrm{~B}$ right $\mathrm{I}^{\circ}$ vs $5 \mathrm{~B}$ left $\mathrm{I}^{\circ}$ & $\mathrm{P}<0.05$ \\
\hline
\end{tabular}

Group I ${ }^{\circ}$ right vs Group I left.

(b)

\begin{tabular}{|c|c|}
\hline $1 \mathrm{~B}$ left $\mathrm{I}^{\circ} \mathrm{vs} 1 \mathrm{~B}$ left $\mathrm{II}^{\circ}$ & $\mathrm{P}<0.05$ \\
\hline 1D left $I^{\circ}$ vs $1 \mathrm{D}$ left $\mathrm{II}^{\circ}$ & $\mathrm{P}<0.05$ \\
\hline $1 \mathrm{~F}$ left $\mathrm{I}^{\circ} \mathrm{vs} 1 \mathrm{~F}$ left $\mathrm{II}^{\circ}$ & n.s. \\
\hline $5 \mathrm{~A}$ left $\mathrm{I}^{\circ}$ vs $5 \mathrm{~A}$ left $\mathrm{II}^{\circ}$ & $\mathrm{P}<0.05$ \\
\hline $5 B$ left $I^{\circ}$ vs $5 B$ left $I^{\circ}$ & $\mathrm{P}<0.05$ \\
\hline
\end{tabular}

Group I left vs Group II ${ }^{\circ}$ left.

(c)

$\begin{array}{ll}{\text { 1B right } \mathrm{I}^{\circ} \text { vs } 1 \mathrm{~B} \text { left } \mathrm{II}^{\circ}} & \mathrm{P}<0.05 \\ {\text { 1D right } \mathrm{I}^{\circ} \text { vs } 1 \mathrm{D} \text { left } \mathrm{II}^{\circ}}^{\circ} & \mathrm{P}<0.05 \\ {\text { 1F right } \mathrm{I}^{\circ} \text { vs } 1 \mathrm{~F} \text { left } \mathrm{II}^{\circ}}^{\text {5A right } \mathrm{I}^{\circ} \text { vs } 5 \mathrm{~A} \text { left } \mathrm{II}^{\circ}} & \mathrm{P}<0.05 \\ 5 \mathrm{~B} \text { right } \mathrm{I}^{\circ} \text { vs 5B left } \mathrm{II}^{\circ} & \mathrm{P}<0.05 \\ & \mathrm{P}<0.05\end{array}$

Group I right vs Group II ${ }^{\circ}$ left.

covery period. Group III was a control group. The gene expression of 5- $\mathrm{HT}_{5 \mathrm{~A}}, 5-\mathrm{HT}_{5 \mathrm{~B}}, 5-\mathrm{HT}_{1 \mathrm{~B}}, 5-\mathrm{HT}_{1 \mathrm{D}}$, and $5-\mathrm{HT}_{1 \mathrm{~F}}$ receptors detected in the Gasser ganglia neurons on both sides was set equal to 1 . This reference value was set to normalise the values of the corresponding 5 -HT receptor gene expression in the other groups.

\section{Discussion}

Previous studies have shown that sensory primary neurons of the trigeminal ganglia overexpress growth proteins (alpha-tyrosinated tubulin) and undergo significant terminal sprouting and neosynaptogenesis in response to peripheral axotomy and central deafferentation [1].

The results of the present study show for the first time that the adaptive response of primary trigeminal neurons to injury is complex. It involves not only anatomical remodelling but also significant changes in 5-HT receptor gene expression in primary trigeminal neurons. Specifically, plastic changes were noted on both sides, characterised by a significant increase in the relative expression of the 5-HT receptor genes. Significant differences were noted, however, between the ganglia of the two sides. 


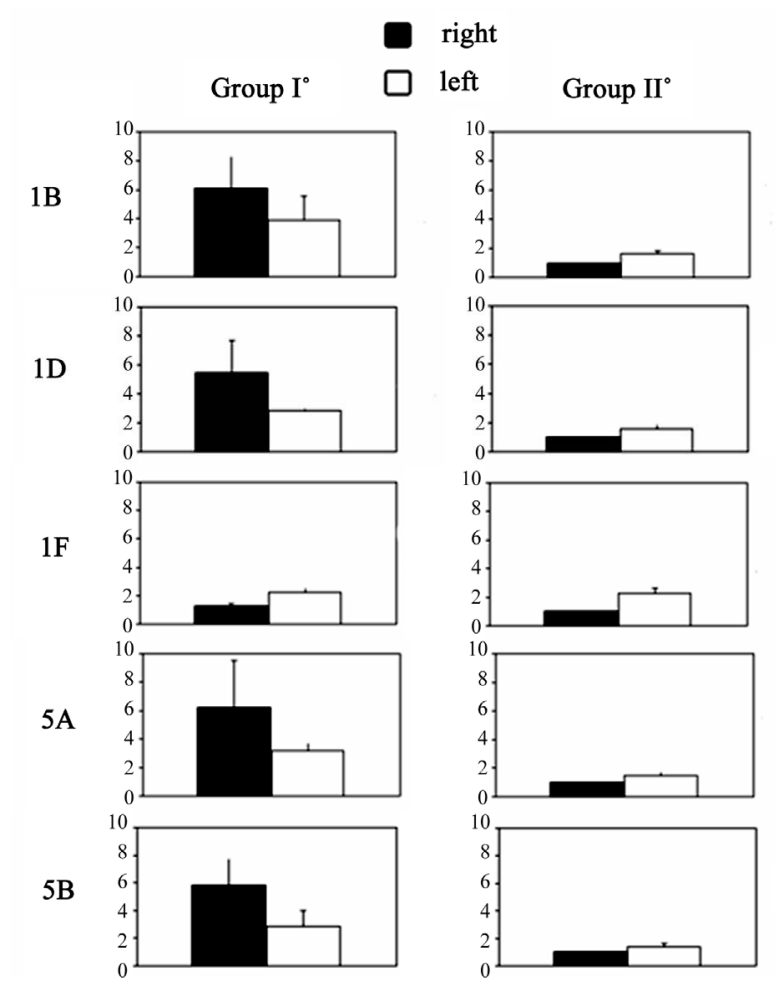

Figure 1. Histograms showing 5-HT receptor gene expression levels (mean \pm SD) in Gasser ganglia neurons on the contralateral (dark columns) and ipsilateral sides (white columns) following unilateral lesions in experimental animals. Group $I^{\circ}$ : unilateral ablation of the meninges and the underlying facial sensory-motor areas of the left side; Group $\mathrm{II}^{\circ}$ : unilateral ablation of the meninges on the left side, without damaging the underlying cerebral cortex. In both groups: scales were expressed in arbitrary units, normalised to a value of 1 assigned to the mRNA level of each 5-HT gene in the trigeminal ganglia of control animals (Group III).

Except for 5- $\mathrm{HT}_{1 \mathrm{~F}}$, the expression of 5-HT receptors was higher in primary trigeminal neurons contralateral to the ablated cortex. Given that the corticotrigeminal pathway predominantly projects to the contralateral side ([10], for review), it is not surprising that a greater response was noted in the contralateral ganglia neurons, where the effects of deafferentation were the greatest. As a conesquence of decortication and degeneration of the corticotrigeminal pathway, the central afferent terminals of the primary neurons lose the presynaptic cortical modulating signals [11,12].

Following the degeneration of the cortico-trigeminal pathway, the central terminations of the ganglia neurons at the level of the sensory nuclei contacted vacant synaptic sites of projecting and non-projecting trigeminal neurons [13], leading to reinnervation [14]. The primary afferent neosynaptogenesis, observed at the level of the trigeminal nuclei complex contralateral to the ablated cortex in our previous study [1], may indicate the necessity of 5-HT receptor up-regulation in ganglia cell bodies, as demonstrated by our present results.

The exception in the present study was the $5-\mathrm{HT}_{1 \mathrm{~F}}$ receptor. It was expressed more strongly in ganglia neurons ipsilateral to the surgical injury. We believe that this result may be a consequence of peripheral axotomy of the trigeminal-vascular ganglia neurons that reached the ipsilateral meningeal vessels and was damaged by the meningeal ablation. The peripheral axonal damage leads to a reduction in afferent signals to the cell bodies, and the increased expression of $5-\mathrm{HT}_{1 \mathrm{~F}}$ receptor genes in these neurons may be a plastic response of the vascularmeninges trigeminal neurons to peripheral deafferentation.

In regard to the functional implications of the present study, $5-\mathrm{HT}_{1 \mathrm{~F}}$ is involved in sterile inflammation, including extravascular plasma protein leakage and vasodilatation [15-17, for review]. Furthermore, in the Gasser's ganglia, $92 \%$ of the $5-\mathrm{HT}_{1 \mathrm{~F}}$ receptor-labelled neurons, which are a target of migraine drugs [16], are glutamatergic. Glutamate is involved in direct nociceptive central transmission, as both $\mathrm{N}$-methyl d-aspartate (NMDA) and non-NMDA receptor antagonists attenuate noxious stimuli-evoked responses in the trigeminal nucleus caudalis [18]. Therefore, it is possible that glutamate [18] and calcitonin gene-related peptide (CGRP) [19] released by central terminals of ganglia neurons mediate nociceptive transmission to the CNS. Therefore, increased expression of $5-\mathrm{HT}_{1 \mathrm{~F}}$ receptor detected ipsilaterally to the ablated meninges may modulate the central transmission of painful sensations.

Finally, the actions of 5-HT can be divided into preand postsynaptic effects. In the latter, the primary action of 5-HT is inhibitory, i.e., 5-HT induces an inhibitory postsynaptic potential (IPSP), thereby exerting antinociceptive effects in dorsal horn neurons [20,21]. By contrast, in the former case, the action of 5-HT is facilitatory, i.e., 5-HT depresses the mediated $\gamma$-aminobutyric acid (GABA) inhibition at the level of primary afferents and presumably acts directly on the $5-\mathrm{HT}_{1 \mathrm{~A}}$ receptors of primary afferent terminals [22].

\section{Trigeminal Ganglia Neurons also Express 5-HT $(5)$ Receptors}

Our results show that 1 ) in addition to the $5-\mathrm{HT}_{1}$ receptor, the primary trigeminal neurons also express the $5-\mathrm{HT}_{(5)}$ receptor; and 2) the expression was increased in the ganglia contralateral to the ablated cortex. Even in this case, the overexpression of these receptors may represent an adaptive response of the primary trigeminal neurons to the loss of the cortico-trigeminal pathway that pre-synaptically modulated their central afferents targeting the $\mathrm{V}$ nuclei. The functional significance of these receptors, however, is unknown. It has been shown that the $5-\mathrm{HT}_{(5)}$ receptors appear to couple $\mathrm{G}$ proteins, and the primary 
coupling appears to be through Gi/o to inhibit adenylyl cyclase activity [23-24], whose activation opens $\mathrm{K}^{+}$channels. The G(i)G(o)-mediated signal transduction and its strong presence in the raphe and other brainstem and pons nuclei suggest mechanisms similar to those of $5-\mathrm{HT}_{(1)}$ receptors. The $5-\mathrm{HT}_{5 \mathrm{~A}}$ receptor is also localised in two superficial layers of the dorsal horn and is involved in the spinal modulation of pain [21]. It is possible that they exert the same function at trigeminal level, although further experiments are necessary to verify this hypothesis.

\section{Conclusions}

Previous studies have shown a significant increase in cytoscheletal proteins gene expression of trigeminal ganglia neurons in response to injury. This may serve the purpose of neuronal repair and the synaptic rearrangement of axonal terminations. However, the present results show that the adaptive response of primary trigeminal neurons to injury is rather complex. It involves not only anatomical remodelling but also significant changes in the gene expression of membrane receptors. In particular, the present study analysed the adaptive responses of 5HT receptors on trigeminal ganglia neurons, as they are significantly involved in pain transmission.

The axotomy of the peripheral terminations and the pre-synaptic deafferentation of the central afferents of the trigeminal ganglia neurons, targeting the $\mathrm{V}$ nuclei complex, resulted in an up-regulation of 5-HT receptor gene expression dependent upon the injury extension. These plastic changes may significantly influence the sensory signals code of the primary trigeminal neurons at the central level. Therefore, this may explain some aspects of the distortion of sensory signals observed in neuropathic pain states and may lead to new pharmacological interventions.

\section{Methods}

The experiments were performed on Wistar rats weighing 300 - 350 g (Morini S. Polo D’Enza, Italy) in accordance with current institutional guidelines for the care and use of experimental animals. The rats were housed in a temperature-controlled room $\left(23^{\circ} \mathrm{C} \pm 1{ }^{\circ} \mathrm{C}\right)$ and a $12: 12$ light/dark cycle, with lights on from 07:00 to 19:00 hours. Laboratory chow and water were available ad libitum, and the experiments were conducted from 9:00 to 17:00 h. The protocol was approved by the Italian Ministry of Health and the local Veterinary Public Health Service. All procedures were performed according to the princeples of the Helsinki Declaration.

All animals ( $n=23)$ were anaesthetised with an intraperitoneal injection of diazepam (30 mg/ $\mathrm{kg}$ ) and ketamine hydrochloride (45 mg/kg). Then, under aseptic conditions, the animals were submitted to unilateral ex- tensive craniotomy to expose the supero-lateral left hemisphere. The animals were subdivided into three groups.

\subsection{Group I $(n=12)$. Primary Trigeminal Neurons Underwent both Peripheral Axotomy and Pre-Synaptic Deafferentation of Their Central Afferents}

The meninges covering the supero-lateral left hemisphere were removed along the edges of a large craniotomy, and the underlying facial sensory and motor cortices (SI-SII and MI-MII) [25] were ablated by suction. The ablation of the cerebral cortex (SI-SII and MI-MII), determined the cortico-trigeminal pathway degeneration, particularly on the contralateral side, as the cortico-trigeminal pathway prevailingly crossed the midline [26]. Furthermore, as the cortico-trigeminal pathway presynaptically modulates the central afferents of the primary trigeminal neurons and post-synaptically influences the second order neurons of the trigeminal nuclei [26,27], the ablation of the cerebral cortex (SI-SII and MI-MII) may simultaneously induce two significant deafferentations.

The present experiments were based on our previous study [1]. Immediately after surgery, the peripheral terminations of the primary trigeminal-vascular neurons innervating the left meningeal vessels were axotomised. Fifteen days after the surgery, the cortico-trigeminal pathway was degenerated [28]; thus, the central terminations of the primary trigeminal neurons targeting the trigeminal nuclei lost the pre-synaptic modulation of the corticotrigeminal pathway, and the same trigeminal nuclei were deafferentated.

In the experimental animal group, the surgery induced ipsilateral axotomy of the peripheral terminations of the primary trigeminal-vessel neurons, whereas the sensorymotor area cortical ablation induced deafferentation of their central projections to the trigeminal nuclei, particularly on the contralateral side (Figure 2).

\subsection{Group II $(n=8)$. This Group Underwent Only a Peripheral Axotomy of the Primary Trigeminal Neurons}

Under general anaesthesia, a left frontal-temporal-parietal craniotomy at SI-SII and MI-MII was performed on the animals as in Group I. Only the meninges covering the left superior lateral hemisphere were removed, without damaging the underlying cortical areas (Figure 3). Therefore, the animals underwent only a peripheral axotomy of the primary trigeminal-vascular neurons innervating the meninges.

\subsection{Group III $(n=3)$. Sham-Operated Animals}

These animals underwent a sham operation and served as controls. Under general anaesthesia, a left frontal-tem- 


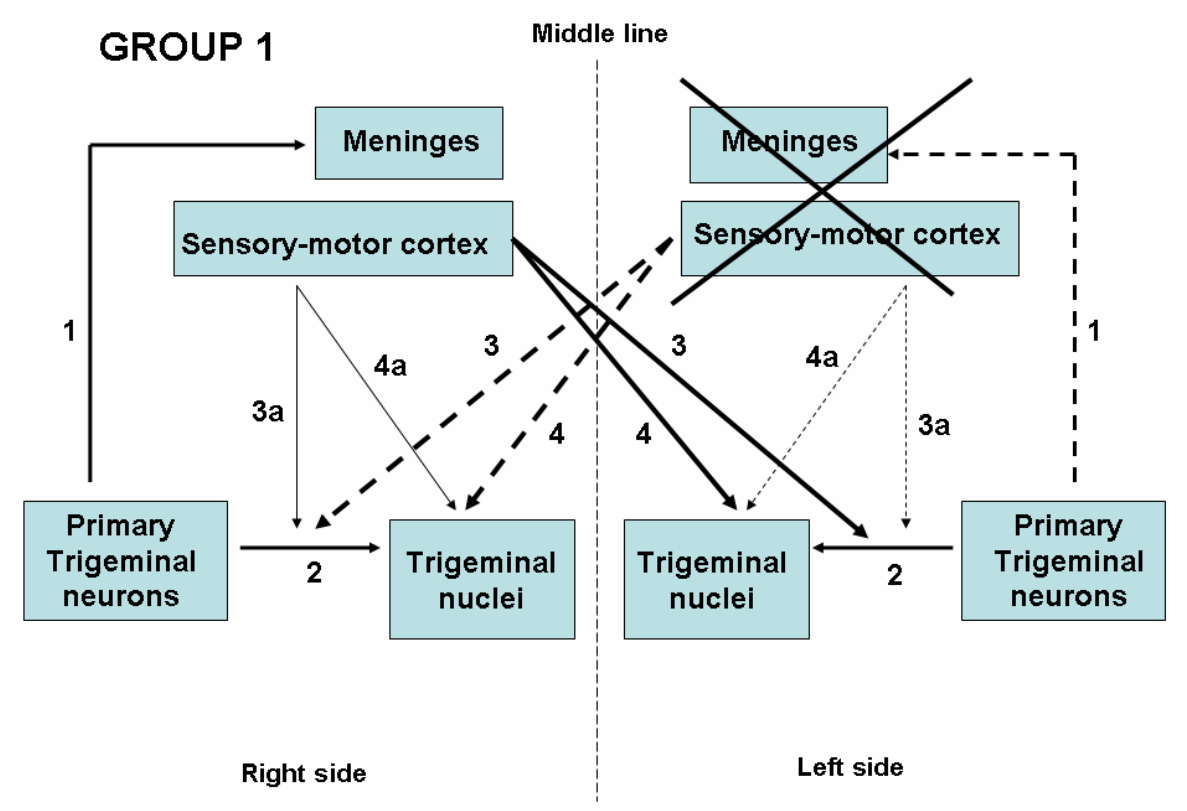

Figure 2. Schematic drawing of the effects of lesions in Group 1 animals. Unilateral ablation of the meninges and the sensory-motor cortex (cross) induced peripheral axotomy of the ipsilateral primary trigeminal neurons (dotted line 1) and degeneration of the cortico-trigeminal pathway, particularly in the contralateral side (dotted lines 3 - 4) and, to a lesser extent, ipsilaterally (dotted lines 3a - 4a). (Line 2): Central terminations of primary trigeminal neurons.

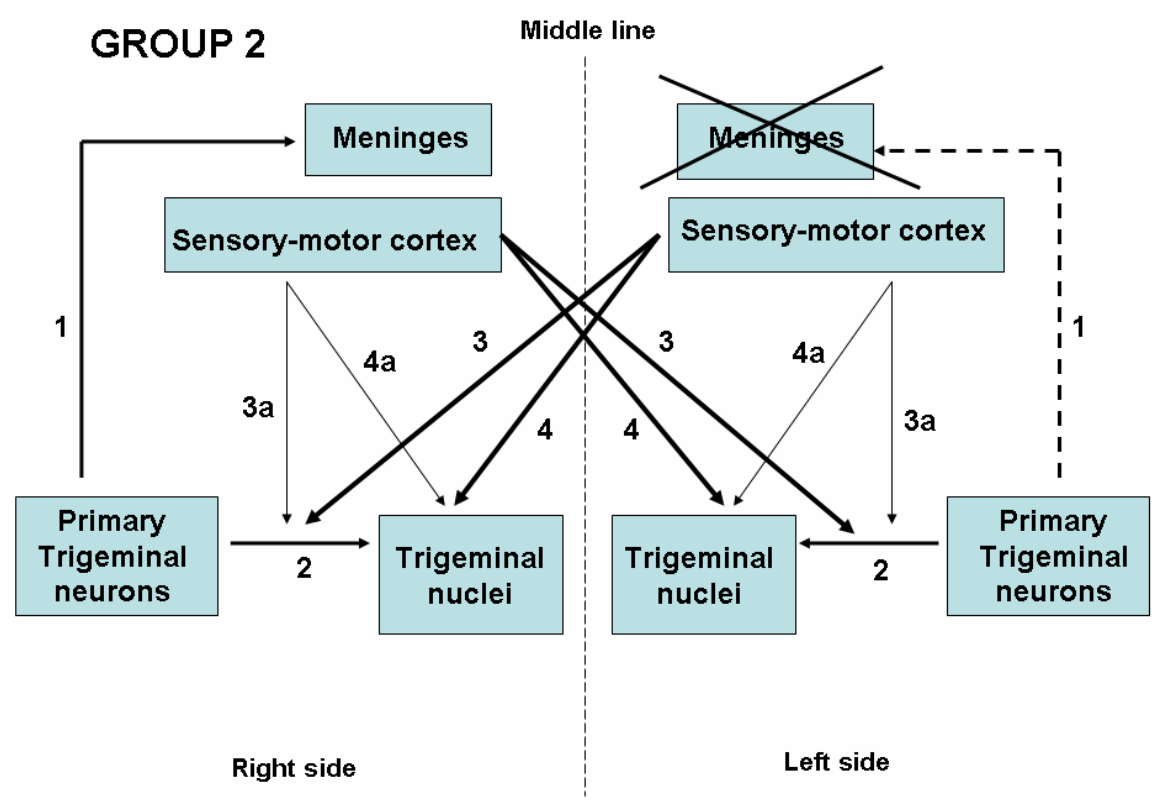

Figure 3. Schematic drawing of the effects of lesions in Group 2 animals. Unilateral ablation of the meninges (cross) induced peripheral axotomy of the ipsilateral primary trigeminal neurons (dotted line 1). Line 2: Central terminations of primary trigeminal neurons; Lines 3 - 4: crossed and Lines 3a - 4a: ipsilateral cortico-trigeminal pathway.

poral-parietal craniotomy at SI-SII and MI-MII was performed as in Group I, and the underlying supero-lateral hemisphere was carefully exposed, sparing the meninges as well as the cerebral cortex (Figure 4).

Following surgical recovery, the animals in all groups were monitored twice a day by observers blinded to the experimental goals. Fifteen days after surgery, the animals were sacrificed by decapitation. The trigeminal (Gasser's) ganglia (TG) were bilaterally removed, and RNA isolation procedures and subsequent quantification of the gene expression level of the $5-\mathrm{HT}_{1 \mathrm{~B}}, 5-\mathrm{HT}_{1 \mathrm{D}}$, $5-\mathrm{HT}_{5 \mathrm{~A}}, 5-\mathrm{HT}_{5 \mathrm{~B}}$, and $5-\mathrm{HT}_{1 \mathrm{~F}}$ receptors were conducted. 


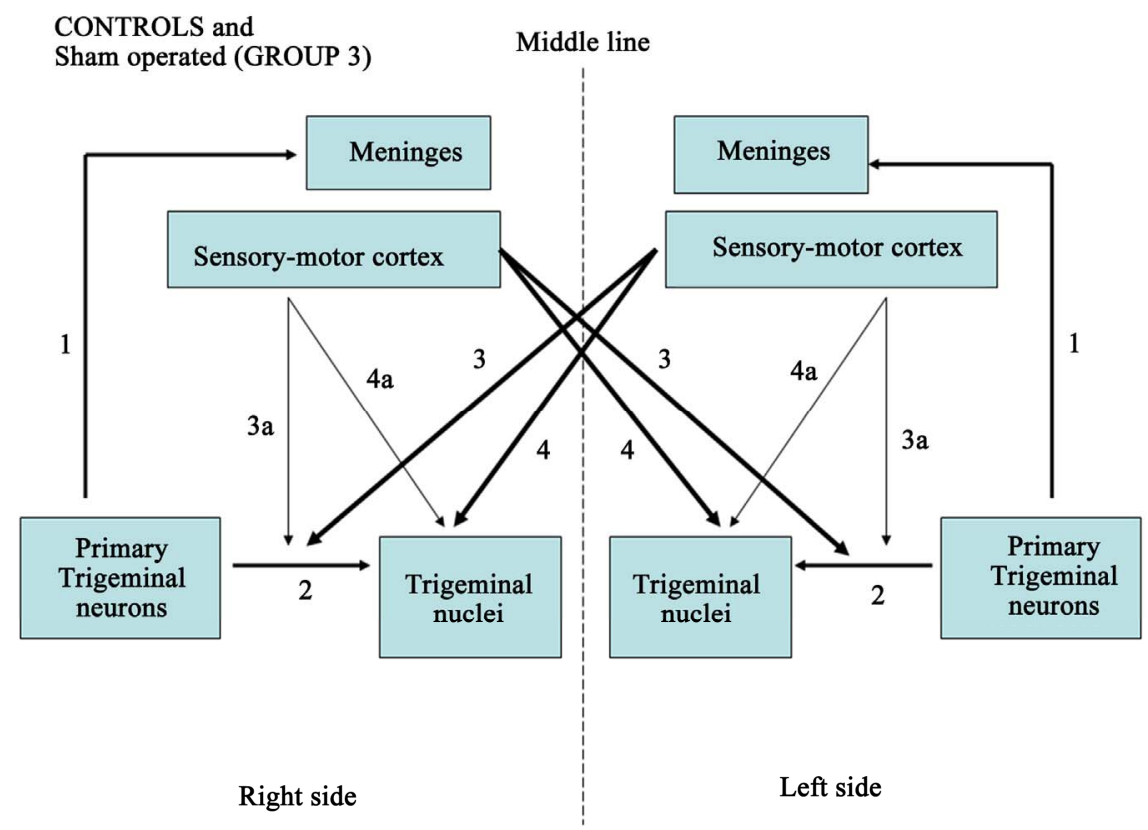

Figure 4. Schematic drawing of the integrity of the neural connections in sham-operated Group 3 animals. Line 1: Peripheral terminations of the primary trigeminal neurons; Line 2: Central terminations of primary trigeminal neurons; Lines 3 - 4: crossed and Lines 3a - 4a ipsilateral cortico-trigeminal pathway.

\subsection{Detection of Quantity and Quality of the RNA}

RNA isolation was performed using RNeasy Lipid Tissue Mini Kits (Qiagen). The quantity and quality weredetected in each ganglion sample using a 2100 Bioanalyzer Kit (RNA 6000 Nano kit; Assay: Eukaryote Total RNA Nano assay) to determine the RNA integrity number (RIN). Only samples with RIN > 7 were considered for subsequent procedures.

\subsubsection{Trigeminal Ganglia Real-Time PCR}

The levels of the 5-HT receptor gene expression were determined using the following procedure. A value of 1 was assigned to the mRNA level of each 5-HT receptor gene in the TG of control animals (Group III), and the relative level of the corresponding 5-HT receptor gene in the experimental animals were normalised accordingly.

\subsubsection{RNA Isolation}

For each ganglion, total RNA was isolated using silicabased membrane purification according to the manufacturer's protocol (QIAamp RNA Blood Mini Kit, QIAGEN, Hilden, Germany). The tissue samples were homogenised, frozen immediately in liquid nitrogen, and ground into a fine powder under liquid nitrogen. Then, the suspension was transferred to a liquid nitrogen-cooled, RNase-free polypropylene tube, and after vaporising the liquid nitrogen and adding lysis buffer (RLT), it was homogenised using a QIAshredder spin column. High- quality RNA was eluted in $50 \mu \mathrm{L}$ of RNase-free water, and its quantity was evaluated using ultraviolet (UV) spectrophotometry. Total RNA with $\mathrm{OD}_{260} / \mathrm{OD}_{280}>1.6$ was used for real-time reverse transcription PCR.

\subsubsection{Primer and TaqMan Probe Design}

Forward and reverse primers and TaqMan probes were designed using the Beacon Designer 3.0 software (PREMIER Biosoft International, Palo Alto, CA). The following gene sequences are available in GenBank: rat 18S rRNA (XO1117), Rattus norvegicus 5-hydroxytryptamine receptor 5-HT receptor 1B mRNA (NM_022225), $R$. norvegicus 5-HT receptor $1 \mathrm{D}$ mRNA (NM_012852), $R$. norvegicus 5-HT receptor 5A mRNA (NM_013148), $R$. norvegicus 5-HT receptor 5B mRNA (XM_001055046), and $R$. norvegicus 5-HT receptor $1 \mathrm{~F}$ mRNA (NM_ 021857). The sequences of the primers and probes are shown in Table 2.

Preliminary experiments were conducted with each primer pair and probes to determine the annealing temperature that yielded the greatest amount of specific product with the appropriate melting temperature $\left(\mathrm{T}_{\mathrm{m}}\right)$. The acquisition temperature was set $1^{\circ} \mathrm{C}-2^{\circ} \mathrm{C}$ below the $\mathrm{T}_{\mathrm{m}}$ of the specific PCR product.

TaqMan probes were synthesised with the fluorescent reporter dye Texas Red for the 18S rRNA probe and 6-carboxy-fluorescein (FAM) for the 5 -HT receptor ${ }_{5 \mathrm{~A}}$, $5 \mathrm{~B}$, $1 \mathrm{~B}, 1 \mathrm{D}$, and $1 \mathrm{~F}$ probes attached to the 5'-end, and the quencher dye BHQ2 (black hole quencher) for the 18S rRNA probe and 6-carboxy-tetramethyl-rhodamine 
(TAMRA) for the 5-HT receptors $5 \mathrm{~A}, 5 \mathrm{~B}, 1 \mathrm{~B}, 1 \mathrm{D}$, and ${ }_{1 \mathrm{~F}}$ probes, attached to the 3'-end. All primer sets and TaqMan probes were obtained from MWG-Biotech (www.mwg-biotech.com).

\subsubsection{Real-Time Reverse Transcriptase PCR}

The genes were quantified using the iQ5 Multicolor Real-Time PCR Detection System (Bio-Rad Laboratories). For each one-step quantitative RT-PCR, the reaction was carried out in a reaction mixture $(25 \mu \mathrm{L})$ according to the manufacturer's protocol (QuantiTect Probe RT-PCR kit, QIAGEN). The reaction mix consisted of $12.5 \mu \mathrm{L}$ of $2 \times$ Quanti RT-PCR master mix, 5 $\mu \mathrm{L}(1 \mu \mathrm{g})$ total RNA, $1 \mu \mathrm{L}$ (10 pmol for 18sRNA, 20 pmol for 5 -HT receptors ${ }_{5 \mathrm{~A}}, 5 \mathrm{~B}, 1 \mathrm{~B}, 1 \mathrm{D}$, and ${ }_{1 \mathrm{~F}}$ ) of forward primer, $1 \mu \mathrm{L}$ (10 pmol for 18sRNA, 20 pmol for 5-HT receptors ${ }_{5 \mathrm{~A}}, 5 \mathrm{~B}, 1 \mathrm{~B}, 1 \mathrm{D}$, and $\left.{ }_{1 \mathrm{~F}}\right)$ of reverse primer, $1 \mu \mathrm{L}(10$ pmol) of all TaqMan probes, $1 \mu \mathrm{L}(1 \mathrm{U})$ of UNG (Epicentre Biotechnologies; www.epibio.com), $2.25 \mu \mathrm{L}$ of RNase-free $\mathrm{H}_{2} \mathrm{O}$, and $0.25 \mu \mathrm{L}$ of RT-mix. This reaction mixture was pre-incubated for $2 \mathrm{~min}$ at $50^{\circ} \mathrm{C}$ to induce hydrolysis of possible contaminating dUTP-containing template from previous PCRs performed in the laboratory.

The RT-PCR protocol consisted of an initial $30 \mathrm{~min}$ at $50^{\circ} \mathrm{C}$ and $15 \mathrm{~min}$ at $95^{\circ} \mathrm{C}$, followed by 50 cycles at $95^{\circ} \mathrm{C}$ for $15 \mathrm{~s}$ and $60^{\circ} \mathrm{C}$ for $30 \mathrm{~s}$. All samples were tested in duplicate. The PCR cycle number at which each assay target reached the threshold detection limit $\left(\mathrm{C}_{\mathrm{T}}\right.$ value) was determined (Table 3).

The RT-PCR assay kinetic reliability was demonstrated by detecting the 18S rRNA transcripts at the same level in all samples. Analysis with a housekeeping gene was used to verify the amount of cDNA in the RT reaction. For all samples, the RT-PCR with the housekeeping gene demonstrated the presence of cDNA template, whereas the RT-PCR negative control indicated its absence. We chose $18 \mathrm{~S}$ rRNA as the reference housekeeping gene because it is conveniently assayed and highly expressed. Although 18S rRNA may be highly variable in samples of different tissues, in our pilot experiments, we verified that in wholly homogenised Gasser's ganglia of control animals, it was relatively stable. Moreover, no significant differences were noted among samples.

Furthermore, we chose to use only one housekeeping gene (18S rRNA) as a reference to normalise the values of single 5-HT receptors because in our experimental protocol, the absolute values of the 5 -HT receptors gene expression were not the goal of the study; rather, we were primarily interested in the possible differences between control and experimental animals.

Table 2. Primers and probes used in real-time $q R T-P C R$ study, their $T_{m}\left({ }^{\circ} \mathrm{C}\right)$ and their GC content $(\%)$.

\begin{tabular}{|c|c|c|c|}
\hline Name & Sequence & $\mathbf{T}_{\mathrm{m}}\left({ }^{\circ} \mathrm{C}\right)$ & GC Content \% \\
\hline 18s rRNA-F & 5’ CTG CCC TAT CAA CTT TCG ATG GTA G 3' & 59.3 & 48 \\
\hline 18s rRNA-R & 5’ CCG TTT CTC AGG CTC ССТ CTC 3' & 59.4 & 61.9 \\
\hline 18s rRNA-Probe & 5’ TexasRed CGA ACC CTG ATT CCC CGT CAC CCG T BHQ2 3’ & 68.2 & 64 \\
\hline 5HTr-1B-F & 5’ ACT GCT TCC ATC ATG CAT CTC T $\quad 3$ ’ & 58.4 & 45.5 \\
\hline $5 \mathrm{HTr}-1 \mathrm{~B}-\mathrm{R}$ & 5’ CGC CCT TTT GGG AGT TCT TTT AG 3' & 60.6 & 47.8 \\
\hline 5HTr-1B-Probe & 5’ FAM TGT CAT CGC CCT GGA CCG CTA CTG G TAMRA 3' & 69.6 & 64 \\
\hline 5HTr-1D-F & 5' CCT CTC CAA TGC CTT CGT A3' & 53.2 & 52.6 \\
\hline 5HTr-1D-R & 5’ TGA CCA AGA TAG AAA CCA GGA 3' & 53.1 & 42.9 \\
\hline 5HTr-1D-Probe & 5' HEX TTA CCA CCA TCC TGC TCA CCA A TAMRA 3' & 59 & 50 \\
\hline 5HTr-5A-F & 5’ CAC CGT GTT CTC CAC TGT 3' & 56 & 55.6 \\
\hline 5HTr-5A-R & 5’ CTT CGC AGC CTT GTA AAT CT 3' & 55.3 & 45 \\
\hline 5HTr-5A-Probe & 5’ FAM CCT TCT ACC TGC CGC TGT GT TAMRA 3’ & 61.4 & 60 \\
\hline 5HTr-5B-F & 5’ ACC TGC GGA GCT TTC TAC 3' & 56 & 55.6 \\
\hline 5HTr-5B-R & 5' GGC CGA ATC GAA ACT TGG 3' & 56 & 55.6 \\
\hline 5HTr-5B-Probe & 5’ FAM CCG TGG TGC TCT TCG TCT ACT TAMRA 3’ & 61.8 & 57.1 \\
\hline $5 \mathrm{HTr}-1 \mathrm{~F}-\mathrm{F}$ & 5’ TCA CGA TTA CAA CAG TGT GG 3' & 55.3 & 45 \\
\hline $5 \mathrm{HTr}-1 \mathrm{~F}-\mathrm{R}$ & 5’ TCA CGG CTA TTT CCT TGG T3’ & 54.5 & 47.4 \\
\hline 5HTr-1F-Probe & 5’ FAM TGT TCA TCT CCG TGC CTC CTC TAMRA 3' & 61.8 & 57.1 \\
\hline
\end{tabular}


Table 3. Average cycle threshold (Ct) value for each of the primer set.

\begin{tabular}{cc}
\hline Primer set & Average cycle threshold $(\mathbf{C t})$ value \\
\hline 18s rRna & 16.53 \\
Htr 1b & 29.93 \\
Htr 1d & 30.16 \\
Htr 5a & 30.79 \\
Htr 5b & 30.02 \\
Htr 1f & 31.44 \\
\hline
\end{tabular}

The results were analysed using standard descriptive statistics to generate mean values and standard deviations. The differences between control and experimental TG and between left and right TG were evaluated using the non-parametric Mann-Whitney $U$-test and the Wilcoxon signed-rank test.

\section{Acknowledgements}

This work was supported by grants from the Fondazione Banco di Sardegna and MIUR.

\section{REFERENCES}

[1] P. L. De Riu, A. Russo, R. Pellitteri, S. Stanzani, G. Tringali, A. M. Roccazzello, G. De Riu, P. Marongiu and O. Mameli, "Primary Afferent Plasticity Following Deafferentation of the Trigeminal Brainstem Nuclei in the Adult Rat,” Experimental Neurology, Vol. 213, No. 1, 2008, pp. 101-107. doi:10.1016/j.expneurol.2008.05.010

[2] J. O. Dostrovsky, K. D. Davis and K. Kawakita, "Central Mechanisms of Vascular Headaches," Canadian Journal of Physiology and Pharmacology, Vol. 69, No. 5, 1991, pp. 652-658. doi:10.1139/y91-097

[3] G. M. Bove and M. A. Moskowitz, "Primary Afferent Neurons Innervating Guinea Pig Dura,” Journal of Neurophysiology, Vol. 77, No. 1, 1997, 299-308.

[4] D. Levy, M. Jakubowski and R. Burstein, "Disruption of Communication between Peripheral and Central Trigeminovascular Neurons Mediates the Antimigraine Action of $5 \mathrm{HT}_{1 \mathrm{~B} / 1 \mathrm{D}}$ Receptor Agonists," Proceedings of the $\mathrm{Na}$ tional Academy of Sciences, Vol. 101, No. 12, 2004, pp. 4274-4279. doi:10.1073/pnas.0306147101

[5] A. M. Strassman and D. Levy, "Response Properties of Dural Nociceptors in Relation to Headache," Journal of Neurophysiology, Vol. 95, No. 3, 2006, pp. 1298-1306. doi:10.1152/jn.01293.2005

[6] A. M. Strassman, S. A. Raymond and R. Burstein, "Sensitization of Meningeal Sensory Neurons and the Origin of Headaches," Nature, Vol. 384, No. 6609, 1996, pp. 560-564. doi:10.1038/384560a0

[7] D. Levy and A. M. Strassman, "Mechanical Response Properties of A and C Primary Afferent Neurons Innervating the Rat Intracranial Dura," Journal of Neurophysiology, Vol. 88, No. 6, 2002, pp. 3021-3031.

\section{doi:10.1152/jn.00029.2002}

[8] D. Levy and A. M. Strassman, "Distinct Sensitizing Effects of the cAMP/PKA Second Messenger Cascade on Rat Dural Mechanonociceptors," Journal of Physiology, Vol. 538, No. 2, 2002, pp. 483-493. doi:10.1113/jphysiol.2001.013175

[9] G. Bonvento, E. T. MacKenzie and L. Edvinsson, "Serotoninergic Innervation of the Cerebral Vasculature: Relevance to Migraine and Ischaemia," Brain Research Reviews, Vol. 16, No. 3, 1991, pp. 257-263. doi:10.1016/0165-0173(91)90009-W

[10] P. M. Waite and D. J. Tracy, "Trigeminal Sensory System,” In: G. Paxynos, Ed., The Rat Nervous System, Academic Press, San Diego, 1995, pp. 714-724.

[11] I. Darian-Smith and T. Yokota, “Cortically Evoked Depolarisation of Trigeminal Cutaneous Afferent Fibres in the Cat,” Journal of Neurophysiology, Vol. 29, No. 2, 1966, pp. 170-184.

[12] I. Darian-Smith and T. Yokota, "Corticofugal Effects on Different Neuron Types within the Cat's Brain-Stem Activated by Tactile Stimulation of the Face," Journal of Neurophysiology, Vol. 29, No. 2, 1966, pp. 185-206.

[13] E. Welker, P. V. Hoogland and H. Van Der Loos, “Organization of Feedback and Feedforword Projections of the Barrel Cortex: A PHA-L Study in the Mouse,” Experimental Brain Research, Vol. 73, No. 2, 1988, pp. 411435. doi:10.1007/BF00248234

[14] J. W. Geddes, K. J. Anderson and C. W. Cotman, "Senile Plaque as Aberrant Stimulating Structure,” Experimental Neurology, Vol. 94, No. 3, 1986, pp. 767-776. doi:10.1016/0014-4886(86)90254-2

[15] M. A. Moscowitz, "Neurogenic Inflammation in the Patophysiology and Treatment of Migrane," Neurology, Vol. 43, No. 6, 1993, pp. S16-S20.

[16] K. W. Johnson, J. M. Schaus, M. M. Durkin, J. E. Audia, S. W. Kaldor, M. E. Flaugh, N. Adham, J. M. Zgombick, M. L. Cohen, T. A. Branchek and L. A. Phebus, "5-HT Receptor Agonists Inhibit Neurogenic Dural Inflammation in Guinea Pigs,” Neuroreport, Vol. 8, No. 9, 1997, pp. 2237-2240. doi:10.1097/00001756-199707070-00029

[17] N. M. Barnes and T. Sharp, “A Review of Central 5-HT Receptors and Their Function," Neuropharmacology, Vol. 38, No. 8, 1999, pp. 1083-1152. doi:10.1016/S0028-3908(99)00010-6

[18] R. J. Storer and P. J. Goadsby, "Trigeminovascular Nociceptive Transmission Involves N-Methyl-D-aspartate and NonN-methyl-D-aspartate Glutamate Receptors,” Neuroscience, Vol. 90, No. 4, 1999, pp. 1371-1376.

[19] C. J. Woolf and Z. Wiesenfeld-Hallin, "Substance P and Calcitonin Gene-Related Peptide Synergistically Modulate the Gain of Nociceptive Flexor Withdrawal Reflex in the Rat,” Neuroscience Letters, Vol. 66, No. 2, 1986, pp. 319323. doi:10.1016/0304-3940(86)90195-3

[20] H. L. Fields, M. M. Heinricher and P. Mason, "Neurotrasmitters in Nociceptive Modulatory Circuits," Annual Review of Neuroscience, Vol. 14, 1991, pp. 219-245. doi:10.1146/annurev.ne.14.030191.001251 
[21] S. Doly, J. Fischer, M.-J. Brisorgueil, D. Vergé and M. Conrath, "5-HT5A Receptor Localization in the Rat Spinal Cord Suggests a Role in Nociception and Control of Pelvic Floor Musculature," Journal of Comparative Neurology, Vol. 476, No. 4, 2004, pp. 316-329.

doi:10.1002/cne.20214

[22] S. Hochman, S. M. Garraway, D. W. Machacek and B. L. Shay, "5-HT Receptors and the Neuromodulator Control of Spinal Cord Function,” In: T. C. Cope, Ed., Motor Neurobiology of the Spinal Cord, CRC Press, Boca Raton, 2001, pp. 1-40.

[23] D. L. Nelson, “5-HT5 Receptors,” Current Drug TargetCNS \& Neurological Disorders, Vol. 3, No. 1, 2004, pp. 53-58. doi:10.2174/1568007043482606

[24] B. Volk, B. J. Nagy, S. Vas, D. Kostyalik, G. Simig and G. Bagdy, "Medicinal Chemistry of 5-HT5A Receptor Ligands: A Receptor Subtype with Unique Therapeutical Potential," Current Topics in Medicinal Chemistry, Vol. 10, No. 5 2010, pp. 554-578. doi:10.2174/156802610791111588

[25] S. P. Wise, E. A. Murray and J. D. Coulter, "Somatotopic
Organization of Corticospinal and Corticotrigeminal Neurons in the Rat," Neuroscience, Vol. 4, No. 1, 1979, pp. 65-78. doi:10.1016/0306-4522(79)90218-5

[26] R. C. Dunn and D. J. Tolber, "The Corticotrigeminal Projection in the Cat. A Study on the Organization of Cortical Projections to the Spinal Trigeminal Nucleus," Brain Research, Vol. 240, No. 1, 1982, pp. 13-25. doi:10.1016/0006-8993(82)90640-0

[27] R. Dubner and B. J. Sessle, "Presynaptic Excitability Changes of Primary Afferents and Corticofugal Fibres Projecting to Trigeminal Brain-Stem Nuclei,” Experimental Neurology, Vol. 30, No. 2, 1971, pp. 223-238. doi:10.1016/S0014-4886(71)80003-1

[28] N. L. Chiaia, C. A. Bennet-Clarke and R. W. Rhoades, "Effects of Cortical and Thalamic Lesions upon Primary Afferent Terminations, Distributions of Projecting Neurons and Cytochrome Oxidase Pattern in the Trigeminal Brain Stem-Complex," Journal of Comparative Neurology, Vol. 303, No. 4, 1991, pp. 600-616. doi:10.1002/cne.903030407 